\title{
Frequency of glucocorticoid resistance and dependency in Crohn's disease
}

\author{
P Munkholm, E Langholz, M Davidsen, V Binder
}

\begin{abstract}
The outcome of the first steroid treatment course was prospectively studied in a regional cohort of 196 patients with Crohn's disease diagnosed 1979-1987. The immediate outcome after 30 days, and the prolonged outcome 30 days after treatment had stopped, are described. In all 109 patients treatment was analysed. Complete remission was obtained in $48 \%$, partial remission in $32 \%$, and no response in $\mathbf{2 0 \%}$ within 30 days of treatment. Among primary responders (complete and partial remission), $55 \%$ remained in prolonged response after treatment had finished, while $45 \%$ relapsed or could not be withdrawn from treatment within one year. Localisation of disease, age, sex or clinical symptoms did not significantly correlate with outcome, which can be summarised as prolonged steroid response in $44 \%$, steroid dependency in $36 \%$, and steroid resistant in $\mathbf{2 0 \%}$ of the patients. (Gut 1994; 35: 360-362)
\end{abstract}

Although steroid treatment has been proved effective $^{12}$ and is generally accepted as the preferable medical treatment in acute, active Crohn's disease, not all patients benefit from such treatment. Some of those who benefit seem to relapse immediately after the treatment has finished. The frequency of steroid resistance and dependency is, however, not well known. ${ }^{3}$

The aim of this study was, from a regional, unselected group of patients, to prospectively analyse the outcome of the first steroid treatment course after diagnosis, judged as immediate and longterm clinical response.

\section{Patients and methods}

A total of 196 patients, living within Copenhagen County, were diagnosed as having Crohn's disease between 1979 and 1987, according to previously published criteria. ${ }^{4}$ Within that period 109 of these patients received at least one systemic steroid treatment course of which the first was the basis for this study. Most of these patients, $92(84 \%)$ had their first steroid course within the year of diagnosis. Only four patients were operated upon with intestinal segment

TABLE I Clinical data of 196 patients with Crohn's disease diagnosed 1979-87 in Copenhagen County

\begin{tabular}{|c|c|c|c|c|c|c|}
\hline & $\operatorname{Sex}(F / M)$ & $\operatorname{Age}(y)^{\star}$ & $\begin{array}{l}\text { Small } \\
\text { and large } \\
\text { bowel }\end{array}$ & $\begin{array}{l}\text { Small } \\
\text { bowel } \\
\text { only }\end{array}$ & $\begin{array}{l}\text { Large } \\
\text { bowel } \\
\text { only }\end{array}$ & Other \\
\hline $\begin{array}{l}\text { Total }(n=196) \\
\text { Steroid treatment }(n=109)\end{array}$ & $\begin{array}{l}1 \cdot 5(116 / 80) \\
2 \cdot 0(72 / 37)\end{array}$ & $\begin{array}{l}31 \cdot 0(12-84) \\
28 \cdot 6(14-84)\end{array}$ & $\begin{array}{l}71(36 \%) \\
37(34 \%)\end{array}$ & $\begin{array}{l}53(27 \%) \\
27(25 \%)\end{array}$ & $\begin{array}{l}67(34 \%) \\
45(41 \%)\end{array}$ & $\begin{array}{l}5(3 \%) \\
0(0 \%)\end{array}$ \\
\hline
\end{tabular}

resection before glucocorticoid treatment. Table I shows the median age, sex, and extent of Crohn's disease at diagnosis. The median observation time was $3 \cdot 4$ years (0-9). Follow up rate was $100 \%$.

Steroid treatment response was assessed at day 30 after start of treatment and 30 days after treatment has been stopped. Extent of disease, clinical symptoms, and paraclinical data as s-haemoglobin, leucocyte count, erythrocyte sedimentation rate (ESR), plasma albumin, and orosomucoid were recorded when the first steroid course was started.

Prednisolone treatment was given orally, initially in a dose of approximately $1 \mathrm{mg} / \mathrm{kg}$ body weight per day, reduced within weeks to a maintenance dose of $10-15 \mathrm{mg}$ and kept at that level for 3.5 months. The duration of prednisolone treatment lasted less than one year in 95 (87\%) of the 109 patients, (median 84 days; range 5-299). Fourteen patients (13\%) had more than one year of steroid treatment (median 691; range 408-1252).

ASSESSMENT OF TREATMENT OUTCOME

Thirty days after start of steroid treatment, the patients were classified in three clinical response categories:

Complete remission - total regression of clinical symptoms declining to $\leqslant 2$ bowel movements/ day, no blood, pus or mucus in faeces, no abdominal pain, fever, weight loss, and extraintestinal symptoms.

Partial remission - regression of clinical symptoms declining to $\leqslant 4$ stools/day, blood, pus, mucus in faeces, or abdominal pain or all four less than daily and no systemic symptoms as fever and weight loss.

No response - no regression of clinical symptoms. Thirty days after prednisolone treatment had finished, irrespective of its length, the following outcome categories were defined:

Prolonged response - maintenance of complete remission or partial remission after treatment had finished.

Dependence - relapse within 30 days after treatment had finished or relapse at dose reduc-

TABLE II Clinical outcome after 30 days of glucocorticoid treatment

\begin{tabular}{lllc}
\hline & $\begin{array}{l}\text { Complete } \\
\text { remission }\end{array}$ & $\begin{array}{l}\text { Partial } \\
\text { remission }\end{array}$ & $\begin{array}{l}\text { Unchanged } \\
\text { or worse }\end{array}$ \\
\hline Total $(\%)(\mathrm{n}=109)$ & $52(48)$ & $35(32)$ & $22(20)$ \\
Small bowel $(\%)(\mathrm{n}=27)$ & $14(52)$ & $8(30)$ & $5(18)$ \\
Large bowel $(\%)(\mathrm{n}=45)$ & $23(51)$ & $15(33)$ & $7(16)$ \\
$\begin{array}{l}\text { Small and large bowel (\%) } \\
(\mathrm{n}=37)\end{array}$ & $15(41)$ & $12(32)$ & $10(27)$ \\
\hline
\end{tabular}



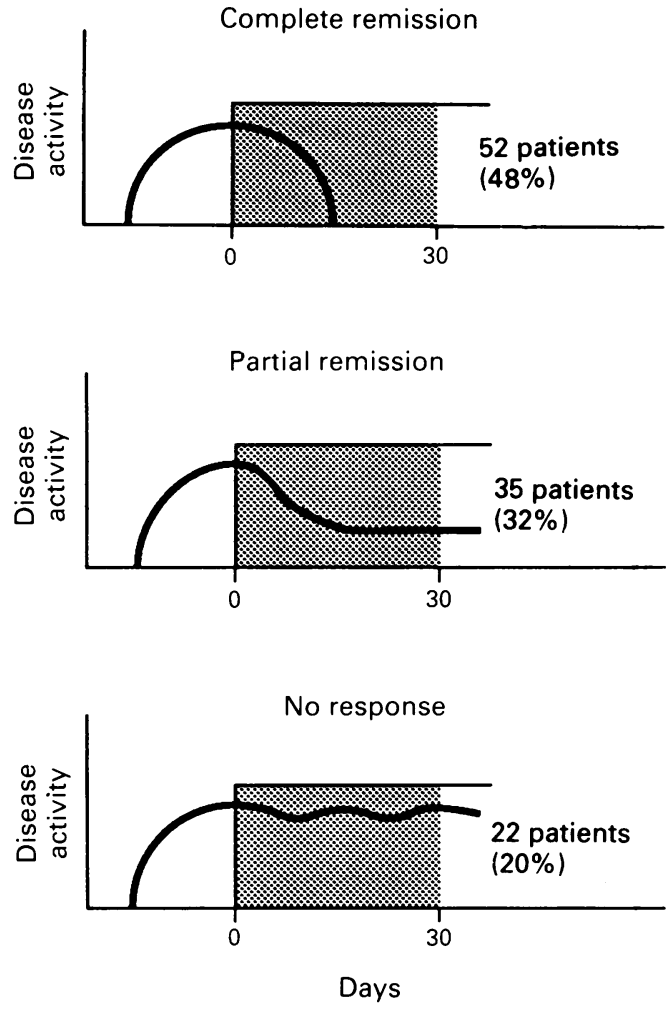

Figure 1: Immediate outcome of the first steroid treatment course in 109 patients with Crohn's disease.
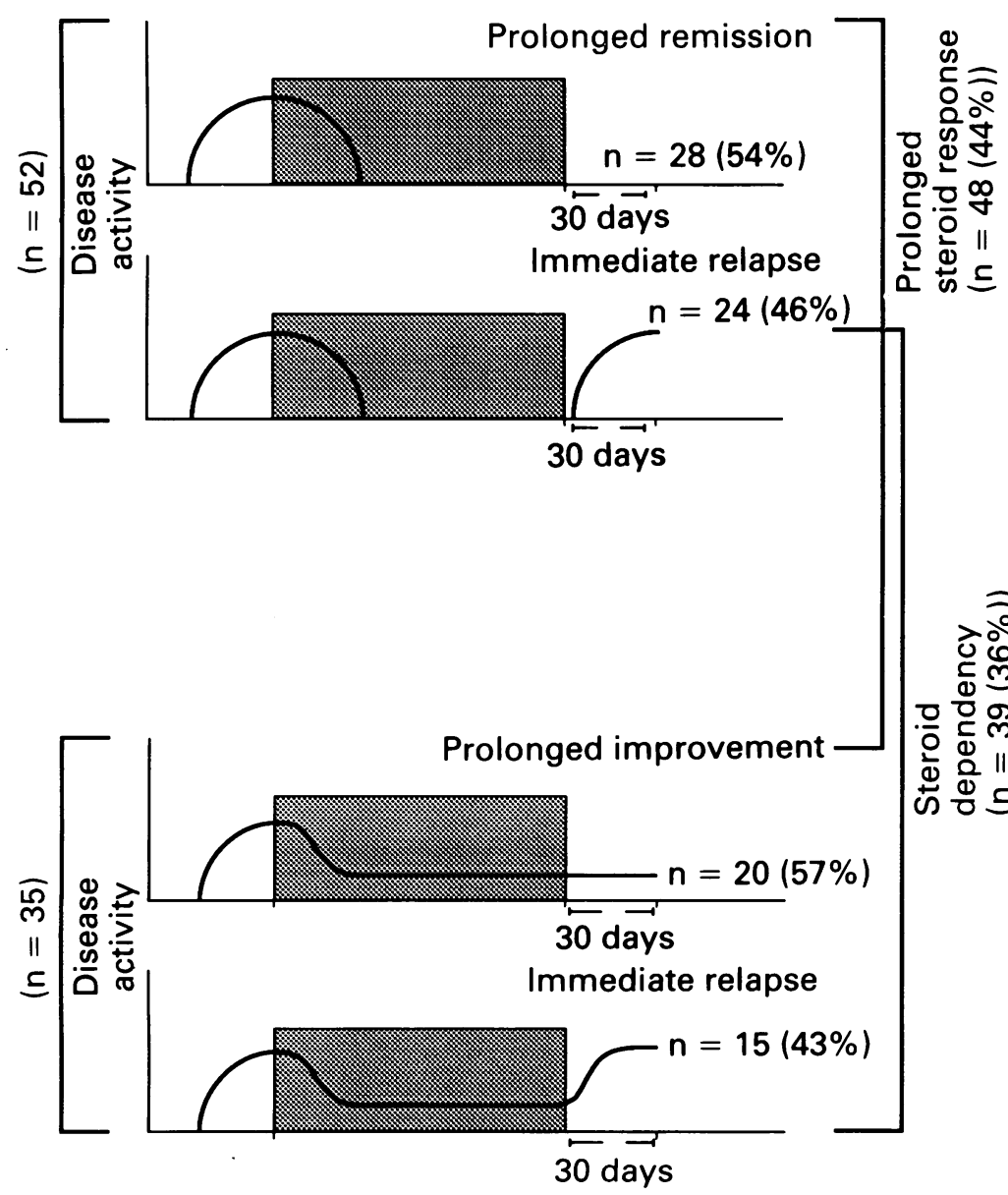

Figure 2: Prolonged outcome after steroid treatment had finished in patients initially obtaining complete and partial remission $(n=87)$.
TABLE III Duration of glucocorticoid treatment in relation to outcome

\begin{tabular}{lc}
\hline Prolonged response & $84(31-280)$ days $^{\star}$ \\
Dependency & $176(41-1252)$ days $^{\star}$ \\
No response & $36(5-203)$ days $^{\star}$ \\
\hline
\end{tabular}

${ }^{\star}$ Median and range.

TABLE IV Frequency of surgical intervention in relation to the finish glucocorticoid treatment

\begin{tabular}{lll}
\hline & $\begin{array}{l}\text { Surgery }<1 \text { month } \\
\text { after treatment ended }\end{array}$ & p Value \\
\hline Prolonged remission $(\mathrm{n}=48)$ & 0 & \\
$\begin{array}{l}\text { Dependency }(\mathrm{n}=39) \\
\text { No response }(\mathrm{n}=22)\end{array}$ & $10(26 \%)$ & $\mathrm{p}<0.00001$ \\
\hline$\chi^{2}=32 \cdot 3, \mathrm{df}=2$. & & \\
\hline
\end{tabular}

tion impeding discontinuation of prednisolone treatment for more than one year.

\section{STATISTICS}

Pearson's $\chi^{2}$ test was used to compare two discrete variables. When comparing a discrete and a continuous variable, the Kruskal-Wallis non-parametric test was used. Value of significance was taken as $\mathbf{5 \%}$.

\section{Results}

Figure 1 shows the immediate outcome within 30 days of steroid treatment. In all $52(48 \%)$ of the patients had achieved a complete clinical remission, $35(32 \%)$ partial remission, and $22(20 \%)$ worsened or were unchanged.

No significant differences in immediate outcome were found between patients with disease localisation in small bowel only, large bowel only, and combined localisation (Table II).

Figure 2 shows the prolonged outcome in patients who improved immediately. Twenty eight patients $(54 \%)$ of those who went into total remission within 30 days also remained free of symptoms 30 days after treatment finished, whereas $24(46 \%)$ patients relapsed. Of these, six could not be withdrawn from treatment and continued receiving steroid treatment for more than one year. Of the patients who improved without reaching complete remission during steroid treatment, $20(57 \%)$ remained improved after treatment finished, while 15 patients $(43 \%)$ relapsed or could not be withdrawn without recurrence within one year of steroid treatment.

The treatment outcomes can then be summarised as: prolonged steroid response in $44 \%$ of the patients, steroid dependency in $36 \%$, and steroid resistance in $20 \%$ of the patients.

Table III shows the length of steroid treatment in the different outcome groups. Of the nonresponders to steroid treatment, $59 \%$ were operated on as a direct consequence of medical treatment failure, as was $26 \%$ of the steroid dependent patients (Table IV). No significant difference in operation rates during the first and second year after treatment was seen between steroid responders, dependents, and nonresponders. 
TABLE V Factors without influence on glucocorticoid treatment

\begin{tabular}{lllll}
\hline Factor & $\begin{array}{l}\text { Prolonged } \\
\text { remission }\end{array}$ & Dependency & $\begin{array}{l}\text { No } \\
\text { response }\end{array}$ & p Value \\
\hline Female/male (\%) & $40 / 46$ & $38 / 35$ & $22 / 19$ & $\mathrm{p}=0 \cdot 9$ \\
Abdominal pain (\%) & 42 & 37 & 21 & $\mathrm{p}=0 \cdot 2$ \\
Diarrhoea (\%) & 51 & 33 & 16 & $\mathrm{p}=0 \cdot 4$ \\
Fever (\%) & 42 & 40 & 18 & $\mathrm{p}=0 \cdot 4$ \\
Localisation & 45 & 37 & 18 & \\
$\quad$ Small bowel (\%) $(\mathrm{n}=27)$ & 46 & 38 & 16 & $\mathrm{p}=0 \cdot 8$ \\
$\quad$ Large bowel (\%) (n=45) & 41 & 32 & 27 & \\
Small and large bowel (\%) $(\mathrm{n}=37)$ & & & & \\
\hline
\end{tabular}

\section{FACTORS INFLUENCING STEROID TREATMENT} OUTCOME

No correlation was seen between clinical symptoms or signs and steroid response. Initial symptoms such as diarrhoea, abdominal pain, weight loss, fever as well as age, sex, duration, and extent of the disease did not influence response. Paraclinical serum laboratory values could not be correlated with outcome of treatment (Table V).

\section{Discussion}

In contrast with a controlled trial, where different treatment regimens are compared, this study describes an evaluation of steroid treatment outcome in a regional cohort of newly diagnosed patients with Crohn's disease.

We aimed at estimating the magnitude of steroid dependency, defined as patients with an immediate improvement but relapsing shortly after treatment finished or after dose reduction. This group of patients are potential candidates for controlled trials with second generation corticosteroids $^{56}$ characterised by a first pass metabolism in the liver ${ }^{7}$ and thus fewer systemic side effects. ${ }^{8}$ In two recent studies, oral budesonide was found to be as efficient as prednisolone in active ileocaecal Crohn's disease. ${ }^{910}$

An immediate response with systemic steroid treatment of 80 per cent is in agreement with results obtained from controlled trials, ${ }^{12}$ whereas the finding that $36 \%$ of all patients treated emerged to be steroid dependent has to our knowledge not previously been shown. According to the treatment policy in our centre, prednisolone treatment has almost exclusively been given orally and only occasionally intravenously. No controlled data pointing to a better effect of glucocorticoids given parenterally rather than perorally exist, assuming the patient has a normal gastric emptying. Our regional patients are referred to one of the gastroenterological departments in the area for treatment and follow up from diagnosis. The very complicated cases suffering from maltreatment or no treatment, as are seen from referral centres are thus avoided.

Prediction of response was not possible by either clinical or paraclinical parameters, thus this study is in agreement with the GETAID study. That study however with somewhat different criteria for disease activity, found a higher rate of complete remission of $92 \%$ although only endoscopic remission in $29 \%$ of the patients. ${ }^{11}$

In conclusion, our analysis of the outcome of the first glucocorticoid treatment course in a regional cohort of 109 patients with Crohn's disease showed that (a) 20 per cent of the patients did not respond at all; (b) although initially responding, 36 per cent of the patients were found to relapse within one month after treatment had stopped or at dose reduction; (c) the outcome of steroid treatment was not correlated with any available clinical or paraclinical characteristics seen before treatment.

This work was supported by grants from Aage Louis-Hansens Mindefond and Nanna Svartz Foundation.

The authors wish to thank Mrs Ingelise Siewerts for skilful help in storing the data and Mrs Bente Ingemann Pedersen for secretarial assistance.

1 Summers RW, Switz DM, Sessions JT, Becktel JM, Best WR, Kern F, et al. National cooperative Crohn's disease study: results of drug treatment. Gastroenterology 1979; 77: 847-69.

2 Malchow H, Ewe K, Brandes JW, Goebell H, Ehms H, Sommer H, et al. European cooperative Crohn's disease study (ECCDS): results of drug treatment. Gastroenterology 1984; 86: 249-66.

3 Lennard-Jones JE. Toward optimal use of corticosteroids in ulcerative colitis and Crohn's disease. Gut 1983; 24: 177-81.

4 Munkholm P, Langholz E, Nielsen OH, Kreiner S, Binder V. Incidence and prevalence of Crohn's disease in the county of Copenhagen, 1962-87: a six fold increase in incidence. Scand F Gastroenterol 1992; 27: 609-14.

5 Brattsand $\mathbf{R}$. Overview of newer glucocorticosteroid preparations for inflammatory bowel disease. Can $\mathcal{F}$ Gastroenterol tions for inflam 4: 407-14.

6 Brattsand R, Thalén A, Roempke K, Källström L, Gruvstad E. Development of new glucocorticosteroids with a very high ratio between topical and systemic activities. Eur $\mathcal{F}$ Respir Dis 1982; 63 (suppl 122): 62-73.

7 Edsbäcker S, Jönsson S, Lindberg C, Ryrfeldt Å, Thalén A. Metabolic pathways of the topical glucocorticoid budesonide in man. Drug Metab Dispos 1983; 11 : 590-6.

8 Singleton JW, Law DH, Kelley ML, Mekhiian HS, Sturdevant RAL. National cooperative Crohn's disease study: adverse reactions to study drugs. Gastroenterology 1979; 77: 870-82.

9 Rutgeerts P, Löfberg R, Malchow H, Lamers C, Olaison G, Jewell D, et al. Budesonide versus prednisolone for the treatment of active ileocecal Crohn's disease: A European multicenter trial. Gastroenterology 1993; 104: A772.

10 Canadian inflammatory bowel disease study group. Oral budesonide in active Crohn's disease: interim report of a placebo controlled randomized trial. Gastroenterology 1993; 104: A675.

11 Modigliani R, Mary J-Y, Simon J-F, Cortot A, Soule J-C, Gendre J-P, et al. Clinical, biological, and endoscopic picture of attacks of Crohn's disease. Gastroenterology 1990; 98: 811-8. 